\title{
Perinatal outcome in cases of severe oligohydramnios
}

\author{
Nilesh Dalal, Anjali Malhotra* \\ Department of Obstetrics and Gynecology, MGMMC and MYH, Indore, Madhya Pradesh, India
}

Received: 20 December 2018

Accepted: 05 March 2019

\section{*Correspondence:}

Dr. Anjali Malhotra,

E-mail: anjalimalhotra.mbbs@gmail.com

Copyright: $\odot$ the author(s), publisher and licensee Medip Academy. This is an open-access article distributed under the terms of the Creative Commons Attribution Non-Commercial License, which permits unrestricted non-commercial use, distribution, and reproduction in any medium, provided the original work is properly cited.

\section{ABSTRACT}

Background: Oligohydramnios is defined as when on ultrasonography the single largest pocket in horizontal and vertical diameter is less than $2 \mathrm{~cm}$ or amniotic fluid index is less than $5 \mathrm{~cm}$. Normal amniotic fluid index is $5-25 \mathrm{~cm}$. The overall incidence is 0.5 to more than $5 \%$. However, the incidence increases in post dated pregnancies as many as $11 \%$. It is increasing these days because of changes in lifestyle and also reduced maternal fluid intake.

Methods: A prospective randomized study was done in Dept of Obstetrics and Gynaecology, MGMMC and MYH, Indore during the period of 6 months from $1^{\text {st }}$ July 2017 to $31^{\text {st }}$ December 2017. It included 200 cases from all the antenatal patients attending Antenatal OPD in routine and emergency and who are admitted in MYH beyond 28 weeks of pregnancy.

Results: Most of the perinatal cases nearly $64 \%$ of babies were handover, $26 \%$ were IUDs (intra uterine devices) and rest $10 \%$ requiring neonatal care in nursery. The color Doppler changes showed normal flow in $54 \%$ in cases with $26 \%$ showing early fetal hypoxia and $14 \%$ showing uteroplacental insufficiency. Rest of the $6 \%$ cases were IUD. Incidence of IUGR was $50 \%$ in babies most commonly being constitutionally small. About $8 \%$ cases were found to be associated with abruption and $24 \%$ cases were found to be associated with pregnancy induced hypertension. Most common mode of delivery was vaginal delivery in $68 \%$ cases. However, $32 \%$ cases underwent LSCS.

Conclusions: There has been reported cases of sudden IUD in severe oligohydramnios presenting with loss of fetal movements.

Keywords: Abruption, Amniotic fluid index, Color Doppler, IUGR (intrauterine growth restriction), NICU (neonatal intensive care unit), Oligohydramnios, Pregnancy induced hypertension, TSVD (term spontaneous vaginal delivery), VBAC (vaginal birth after caesarean)

\section{INTRODUCTION}

Manning et al, defined Oligohydramnios when the largest pocket on ultrasound in its largest diameter measured less than $1 \mathrm{~cm} .{ }^{1}$ Subsequently they revised this criterion to a single pocket measuring $2 \mathrm{~cm}$ in both vertical and horizontal planes. Phelan who described amniotic fluid index defined Oligohydramnios as an AFI less than $5 \mathrm{~cm}^{2}{ }^{2}$ Quantitatively, Oligohydramnios is defined as an AFV $<300-500 \mathrm{ml}$ after the midtrimester. The reported incidence of Oligohydramnios varies between 0.5 to $5 \%$ this complicates 2.3 to $3.9 \%$ of pregnancies.
Oligohydramnios may be due to a variety of conditions, including urinary tract abnormalities such as renal agenesis, bilateral renal obstruction, bilateral renal dysplasia, and posterior urethral valves or atresia; and prerenal abnormalities, including utero placental insufficiency leading to IUGR, preterm premature rupture of the membranes (PROM), and post-term pregnancy. The common clinical features are smaller symphysio fundal height, fetal malpresentation, undue prominence of the fetal parts and reduced amount of AF. Usually the degree of Oligohydramnios is proportional to the severity of placental hypo perfusion and IUGR (intra uterine 
growth restriction). The most likely cause of oligohydramnios in IUGR babies is decreased urine output. ${ }^{3}$ Complications may include cord compression, musculoskeletal abnormalities such as facial distortion and clubfoot, pulmonary hypoplasia and intrauterine growth restriction. Amnion nodosum is also frequently present (nodules on the fetal surface of the amnion). Even a moderate reduction in AFV is associated with abnormal FHR, meconium stained liquor which often requires CS and may result in perinatal morbidity and/or mortality. ${ }^{4}$ The amniotic fluid volume rises progressively during gestation until approximately 32 weeks. From 32 weeks to term the mean amniotic fluid volume is relatively constant about $700-800 \mathrm{ml}$. After 40 weeks there is progressive decline in amniotic fluid volume average of about $400 \mathrm{ml}$ at 42 weeks. Amniotic fluid volume along with gestational age, it also correlates with fetal and placental weight. The severity of oligohydramnios is associated with degree of IUGR and it reflects the placental dysfunction. ${ }^{5}$

Phelan et al, have recommended that labor induction be considered in patients with oligohydramnios (AFI $<5 \mathrm{~cm}$ ) to reduce the increased risk of fetal death and morbidity. ${ }^{2}$ An antepartum amniotic fluid index (AFI) of $5 \mathrm{~cm}$ or less is a predictor of adverse perinatal outcome in terms of meconium staining, cesarean section for fetal distress, birth weight, low Apgar scores and cord $\mathrm{pH} .{ }^{6}$ AFI of $>18 \mathrm{~cm}$ is taken as cut-off point for normal limit of AFI. Pregnancy complicated with polyhydramnios is also classified as high risk. AFV can be measured by dyedilution techniques and by direct quantification at the time of caesarean delivery, but both methods are invasive, require laboratory support, and when measured at the time of operative abdominal delivery, cannot be used serially to evaluate high-risk pregnancies. ${ }^{7}$ The limitation of the direct AFV measurement led to the use of ultrasonic AFV estimation. Ultrasonography is noninvasive and can clinically quantitate the AFV. There are various reported ultrasonographic modalities to assess AFV like (1) single deepest pocket (2) 2-diameter pocket, and (3) AFI by 4-quadrant method. Since the introduction of AFI by Phelan et al, a rapid semi-quantitative assessment of AFV can be performed quickly, is easily taught, and is reproducible. ${ }^{6}$

The aim and objectives of this study were to study the perinatal outcome in cases of severe oligohydramnios; to study the Color Doppler changes evident in cases of severe oligohydramnios; to study the incidence of IUGR babies in cases of severe oligohydramnios; to study the incidence of High risk factors e.g. Abruption, preeclampsia in association with severe oligohydramnios and to study the pattern of mode of delivery in cases of severe oligohydramnios.

\section{METHODS}

A prospective randomized study was conducted in Department of Obstetrics and Gynaecology in a tertiary care hospital in MGMMC and MYH, Indore during the period of 6 months from 1st July 2017 to 31st December 2017. The cases were allocated as per inclusion and exclusion criteria. It was a prospective randomized study. Sample size consists of 200 cases.

\section{Inclusion criteria}

- All the antenatal patients attending Antenatal OPD in routine and emergency and who are admitted in MYH beyond 28 weeks of gestation with diagnosis of oligohydramnios on USG.

\section{Exclusion criteria}

- All the antenatal patients with less than 28 weeks of gestation.

\section{RESULTS}

Table 1 showing the association of parity with oligohydramnios; with increasing parity, Incidence of oligohydramnios decreases. The incidence was $42 \%$ in primigravida followed by $23 \%$ in third gravida patients.

Table 1: Parity status in cases with oligohydramnios.

\begin{tabular}{|l|l|l|}
\hline Parity status & $\begin{array}{l}\text { Number of } \\
\text { cases }\end{array}$ & $\begin{array}{l}\text { Percentage of } \\
\text { cases }\end{array}$ \\
\hline G1P0 & 84 & 42 \\
\hline G2P1 & 32 & 16 \\
\hline G3P2 & 46 & 23 \\
\hline G4P3 & 24 & 12 \\
\hline G5P4 & 14 & 7 \\
\hline
\end{tabular}

Table 2 showing the association of age with oligohydramnios; with increasing age, Incidence of oligohydramnios decreases. The incidence was highest of $35 \%$ in between age group of $20-25$ years.

Table 2: Age group in cases with oligohydramnios.

\begin{tabular}{|l|l|l|}
\hline $\begin{array}{l}\text { Age group } \\
\text { (in years) }\end{array}$ & $\begin{array}{l}\text { Number of } \\
\text { cases }\end{array}$ & $\begin{array}{l}\text { Percentage of } \\
\text { cases }\end{array}$ \\
\hline$<20$ & 34 & 17 \\
\hline $20-25$ & 70 & 35 \\
\hline $25-30$ & 46 & 23 \\
\hline $30-35$ & 32 & 16 \\
\hline$>35$ & 18 & 9 \\
\hline
\end{tabular}

Table 3 showing the association of mode of delivery with oligohydramnios; Most common used mode of delivery was normal vaginal delivery in $43 \%$ followed by LSCS in $41 \%$.

Table 4 showing perinatal outcome in cases with oligohydramnios; $64 \%$ of the babies were alive and healthy and about $26 \%$ were NICU admissions. 
Table 3: Mode of delivery in cases with oligohydramnios.

\begin{tabular}{|l|l|l|}
\hline $\begin{array}{l}\text { Mode of } \\
\text { delivery }\end{array}$ & $\begin{array}{l}\text { Number of } \\
\text { cases }\end{array}$ & $\begin{array}{l}\text { Percentage of } \\
\text { cases }\end{array}$ \\
\hline Normal labour & 86 & 43 \\
\hline LSCS & 82 & 41 \\
\hline Preterm labour & 16 & 8 \\
\hline VBAC & 6 & 3 \\
\hline TSVD & 20 & 10 \\
\hline
\end{tabular}

Table 4: Perinatal outcome in cases with oligohydramnios.

\begin{tabular}{|l|l|l|}
\hline Perinatal outcome & $\begin{array}{l}\text { Number } \\
\text { of cases }\end{array}$ & $\begin{array}{l}\text { Percentage } \\
\text { of cases }\end{array}$ \\
\hline Alive and healthy & 128 & 64 \\
\hline Intrauterine deaths & 20 & 10 \\
\hline NICU admissions & 52 & 26 \\
\hline
\end{tabular}

Table 5 showing color Doppler changes in cases with oligohydramnios; most cases $(54 \%)$ had normal color flow pattern. However,26\% cases showed early fetal hypoxia and $14 \%$ showed Uteroplacental insufficiency.

Table 5: Color Doppler changes.

\begin{tabular}{|l|l|l|}
\hline Color Doppler & $\begin{array}{l}\text { Number of } \\
\text { cases }\end{array}$ & $\begin{array}{l}\text { Percentage of } \\
\text { cases }\end{array}$ \\
\hline Normal flow & 108 & 54 \\
\hline Early fetal hypoxia & 52 & 26 \\
\hline $\begin{array}{l}\text { Uteroplacental } \\
\text { insufficiency }\end{array}$ & 28 & 14 \\
\hline
\end{tabular}

Table 6 showing color Doppler changes in cases with oligohydramnios; about $64 \%$ and $60 \%$ had normal color flow pattern in umbilical artery and middle cerebral artery respectively. However, 18\% showed increased flow pattern and reversal of flow in $16 \%$ cases in umbilical artery.

Table 6: Color Doppler changes in umbilical artery and middle cerebral artery.

\begin{tabular}{|l|l|l|l|l|}
\hline $\begin{array}{l}\text { Color Doppler } \\
\text { changes }\end{array}$ & Umbilical artery & $\begin{array}{l}\text { Umbilical artery } \\
\text { (in percentage) }\end{array}$ & $\begin{array}{l}\text { Middle cerebral } \\
\text { artery }\end{array}$ & $\begin{array}{l}\text { Middle cerebral artery } \\
\text { (in percentage) }\end{array}$ \\
\hline Normal & 128 & 64 & 120 & 60 \\
\hline Increased & 36 & 18 & 36 & 18 \\
\hline Decreased & 4 & 2 & 44 & 22 \\
\hline Reversal of flow & 32 & 16 & - & - \\
\hline
\end{tabular}

Table 7 showing causes associated with oligohydramnios; most common cause of oligohydramnios was constitutional (50\%) followed by Pregnancy induced hypertension in $44 \%$ of cases. Even on applying statistical tests it was found to be significant with p-value less than 0.05 .

Table 7: Causes associated with oligohydramnios.

\begin{tabular}{|l|l|l|}
\hline $\begin{array}{l}\text { Causes of } \\
\text { oligohydramnios }\end{array}$ & $\begin{array}{l}\text { Number } \\
\text { of cases }\end{array}$ & $\begin{array}{l}\text { Percentage } \\
\text { of cases }\end{array}$ \\
\hline $\begin{array}{l}\text { Abruption } \\
\text { Pregnancy induced } \\
\text { hypertension }\end{array}$ & 88 & 8 \\
\hline PROM & 46 & 44 \\
\hline Congenital anomalies & 12 & 6 \\
\hline Post term pregnancy & 38 & 19 \\
\hline Constitutional & 100 & 50 \\
\hline
\end{tabular}

Some risk factors may overlap

Table 8 showing association of IUGR with oligohydramnios; about $61 \%$ of cases were IUGR and AFI was found to be less than $5 \mathrm{~cm}$ and even on applying statistical tests it was found to be significant with p-value less than 0.05 .
Table 8: Association of degree of oligohydramnios with IUGR.

\begin{tabular}{|l|l|l|}
\hline $\begin{array}{l}\text { Degree of } \\
\text { oligohydramnios }\end{array}$ & $\begin{array}{l}\text { Number of } \\
\text { cases }\end{array}$ & $\begin{array}{l}\text { Percentage of } \\
\text { cases }\end{array}$ \\
\hline $\begin{array}{l}\text { Normal AFI } \\
(8.1-12 \mathrm{~cm})\end{array}$ & 6 & 3 \\
\hline $\begin{array}{l}\text { Moderate oligo } \\
(5.1-8 \mathrm{~cm})\end{array}$ & 72 & 36 \\
\hline $\begin{array}{l}\text { Severe oligo } \\
(<5 \mathrm{~cm})\end{array}$ & 122 & 61 \\
\hline
\end{tabular}

Table 9: Complaints in cases with oligohydramnios.

\begin{tabular}{|l|l|l|}
\hline Chief complaints & $\begin{array}{l}\text { Number } \\
\text { of cases }\end{array}$ & $\begin{array}{l}\text { Percentage } \\
\text { of cases }\end{array}$ \\
\hline Leaking & 74 & 37 \\
\hline Loss of fetal movements & 84 & 42 \\
\hline Bleeding per vaginum & 60 & 30 \\
\hline
\end{tabular}

Some cases may have more than 1 complaint

\section{DISCUSSION}

In present study the incidence of IUGR with age group of 20 to 25 years of age comprising $37 \%$ of total number of cases. Malik Rajesh et al, also reported that most of the 
cases IUGR were belong to 21 to 25 years of age, comprising $47 \%$ of the total number of cases of IUGR. The mean maternal age in my study was 22.5 years however, in the study by Krishna et al, mean maternal age was 23.66 years. Incidence of oligohydramnios was more in primipara (42\%) however incidence was highest in primipara (52\%) in study by Krishna et al. However, In my study incidence of IUGR was $50 \%$ most commonly being constitutionally small. ${ }^{8}$ In study by Krishna et al, most common cause of oligohydramnios is idiopathic (52\%) followed by $\mathrm{PIH}$ in $25 \%$ of pregnancies while in my study it was PIH in $44 \%$ of pregnancies followed by PROM in $23 \%$ of pregnancies. ${ }^{9}$

In present study oligohydramnios had significant correlation with IUGR. $61 \%$ cases of IUGR (100 cases) associated with severe oligohydramnios. This marks as oligohydramnios is a screening tool for IUGR. Casey et al, mentioned that oligohydramnios is associated with a significant increased risk of caesarean delivery for fetal distress, a low Apgar score at $5 \mathrm{~min}$ and neonatal acidosis. ${ }^{10}$ Manning et al, studied that oligohydramnios was an exceptionally reliable predictor for IUGR.

In present study, most common reason to perform caesarean was fetal distress which was either due to cord compression or IUGR. $7 \%$ patients were found with fetoplacental insufficiency on Doppler study. Oligohydramnios was related to higher rate of growth retardation and NICU (neonatal intensive care unit) admission. ${ }^{11}$ The operative morbidity is significantly higher in patients with altered Doppler study. In Weiss et al, and Yound $\mathrm{HK}$ et al, it was $71 \%$ and $69.7 \%$ respectively which was comparable to this study. ${ }^{12,13}$ In present study, operative morbidity was $41 \%$.

\section{CONCLUSION}

There has been reported cases of sudden IUD in severe oligohydramnios presenting with loss of fetal movements.

\section{Funding: No funding sources}

Conflict of interest: None declared

Ethical approval: The study was approved by the Institutional Ethics Committee

\section{REFERENCES}

1. Manning FA, Hill LM, Platt LD. Qualitative amniotic fluid volume determination by ultrasound: antepartum detection of intrauterine growth retardation. Am J Obstet Gynecol. 1981;139:254-8.
2. Phelan JP, Smith CV, Broussard P, Small M. Amniotic fluid volume assessment with the fourquadrant technique at 36-42 weeks' gestation. J Reprod Med. 1987;32(7):540-2.

3. Patrelli TS, Gizzo S, Cosmi E, Carpano MG, Di Gangi S, Pedrazzi G, et al. Maternal hydration therapy improves the quantity of amniotic fluid and the pregnancy outcome in third-trimester isolated oligohydramnios: a controlled randomized institutional trial. J Ultra Med. 2012;31(2):239-44.

4. Gupta R, Porwal SK, Swarnkar M, Gupta S. The role of intravenous amino acid infusion in oligohydramnios. Int $\mathrm{J}$ Pharm Sci Res. 2012;3(10):3971-4.

5. Nicolaides KH, Peter MT, Vyas S, Rabbinowitz R, Rosen DJ, Campbell S. Relation of rate of urine production to exygen tension in small for gestational age foetuses. Am J Obstet Gynecol. 1990;162:38791.

6. Nageotte MP, Towers CV, Asat T, Freeman RK. Perinatal outcome with the modified biophysical profile. Am J Obstet Gynecol. 1994;170(6):1672-6.

7. Magann EF, Chauhan SP, Bofil JA, Martin Jr JN. Comaparability of the amniotic fluid index and single deepest pocket measurement in clinical practice. Aust N Z J Obstet Gynecol. 2003;43:75-7.

8. Malik R, Saxena A. Role of colour Doppler indices in the diagnosis of intrauterine growth retardation in high-risk pregnancies. J Obstet Gynecol India. 2013;63(1):37-44.

9. Jagatia K, Singh N, Patel S. Maternal and fetal outcome in oligohydramnios: A study of 100 cases. Int J Med Sci Public Health. 2013;2(3):724-8.

10. Casey BM, McIntire DD, Bloom SL, Lucas MJ, Santos R, Twickler DM, et al. Pregnancy outcomes after antepartum diagnosis of oligohydramnios at or beyond 34 weeks' gestation. Am J Obstet Gynecol. 2000;182:909-12.

11. Manning FA, Platt LD, Sipos L. Antepartum foetal evaluation: development of a biophysical profile. Am J Obst Gynecol. 1980;136(6):787-95.

12. Jandial C, Gupta S, Sharma S, Gupta M. Perinatal outcome after antepartum diagnosis of oligohydramnios at or beyond 34 weeks of gestation. J K Sci. 2007;9(4):213-4.

13. Clark SL, Sabey P, Jolley K. Nonstress testing with acoustic stimulation and amniotic fluid volume assessment: 5973 tests without unexpected fetal death. Am J Obstet Gynecol. 1989;160(3):694-7.

Cite this article as: Dalal N, Malhotra A. Perinatal outcome in cases of severe oligohydramnios. Int J Reprod Contracept Obstet Gynecol 2019;8:1538-41. 